\title{
The Effect of Massive Small Bowel Resection and Oral Epidermal Growth Factor Therapy on SGLT-1 Distribution in Rabbit Distal Remnant
}

\author{
BRIAN M. CHUNG, LAURIE E. WALLACE, ROBERT K. WINKFEIN, EDWARD V. O'LOUGHLIN, \\ JAMES A. HARDIN, AND D. GRANT GALL \\ Gastrointestinal Research Unit, University of Calgary, Calgary, Alberta T2N 4N1, Canada [B.M.C., \\ L.E.W., R.K.W., J.A.H., D.G.G.], and the Children's Hospital at Westmead, Westmead 2145, Sydney, \\ Australia [E.V.O.]
}

\begin{abstract}
Small bowel resection decreases brush border membrane (BBM) glucose uptake kinetics. Oral epidermal growth factor (EGF) returns net glucose transport across intact tissue to control levels despite persistence of a defect in BBM glucose uptake. The purpose of this study was to examine the effects of resection and EGF treatment on sodium-dependent glucose cotransporter 1 (SGLT-1) expression in distal remnant tissue. New Zealand White rabbits $(1 \mathrm{~kg})$ underwent $70 \%$ small bowel resection $(\mathrm{R})$. One group of resected animals (R-EGF) received oral EGF (40 $\mu \mathrm{g} / \mathrm{kg}$, days 3-8). Distal remnant tissue was harvested $10 \mathrm{~d}$ after surgery, and compared with controls (C). Mucosal SGLT-1 mRNA was measured by Northern blot, BBM SGLT-1 content by Western blot, and villus distribution of SGLT-1 protein and mRNA by immunofluorescence and in situ hybridization. Western blot indicated BBM from both resected and EGF-treated tissue had decreased SGLT -1 content $(\mathrm{C}, 0.55 \pm 0.04 ; \mathrm{R}, 0.35 \pm$ 0.04 ; R-EGF, $0.35 \pm 0.03$ trace OD; $n=5 ; p<0.05)$. Northern blot revealed no alterations in mucosal SGLT-1 mRNA content
\end{abstract}

\section{ABSTRACT}

in any group. SGLT-1 protein and mRNA localization in control tissues was characterized by a gradual increase in stain intensity from the base of the villus to the villus tip. Resection altered SGLT-1 protein and mRNA expression along the villus axis with intensity being strongest in the mid-villus region and little expression at the tip of the villus. Oral EGF normalized SGLT-1 protein and mRNA expression to control patterns. Resection alters SGLT-1 protein and mRNA expression along the villus axis, despite no change in total mucosal SGLT-1 mRNA content. EGF normalized villus SGLT-1 protein and mRNA distribution, without altering overall BBM SGLT-1 content or mucosal mRNA levels. (Pediatr Res 55: 19-26, 2004)

Abbreviations
EGF, epidermal growth factor
SGLT-1, sodium-dependent glucose cotransporter 1
BBM, brush border membrane
GAPDH, glyceraldehyde-3-phosphate dehydrogenase

Massive small bowel resection is usually a last resort surgical procedure carried out in response to a number of pathologic insults, including Crohn's disease, ileitis, necrotizing enterocolitis, volvulus, and gut ischemia (1). If more than $70 \%$ of the small intestine is resected, short bowel syndrome can develop. Short bowel patients cannot absorb enough nutrients from their normal oral diet, and need either parenteral (i.v.) or enteral (oral) nutritional supplementation. Complications associated with nutritional supplementation often result in a lower quality of life, and in some cases, result in significant mortality (1-3).

Received September 11, 2002; accepted May 29, 2003.

Correspondence: D. Grant Gall, M.D., Department of Pediatrics, Faculty of Medicine, University of Calgary, 3330 University Drive NW, Calgary, Alberta T2N 4N1, Canada; e-mail: dggall@ucalgary.ca

Supported by a grant from the Canadian Institutes of Health Research.

Current address (B.M.C.): Department of Nephrology, Internal Medicine, Yale School of Medicine.

DOI: 10.1203/01.PDR.0000098500.94041.9B
In neonates, the loss of a significant length of absorptive small bowel can have dire consequences that cannot be offset by supplemental nutrition therapies, and often lead to failure to thrive and eventual mortality $(1,2)$.

Previous studies in our laboratory have demonstrated that resection of $70 \%$ of the small intestine results in significant morphologic and functional adaptation in the distal remnant (4, 5). Villus height, crypt depth, enterocyte proliferation, and migration rate, as well as brush border surface area, are all increased in remnant tissue $(4,5)$. However, despite these adaptations, glucose transport across short-circuited remnant ileal tissue, and ileal BBM glucose uptake kinetics, remain reduced compared with controls $(4,5)$. These data suggest that during the early adaptive phase after surgical resection, enterocyte absorptive surface area increases but there is less SGLT-1 per unit membrane, possibly because of the increased turnover of enterocytes. 
Daily oral dosage with EGF resulted in normalized glucose transport in short-circuited tissues (4) associated with an increase in absorptive surface area above that elicited by resection alone through increases in both luminal diameter and microvillus height (5). Oral EGF also normalized enterocyte migration rate to control values but had no effect on enterocyte proliferation. However, despite the recovery of transport function in intact tissue, BBM obtained from EGF-treated resected animals still demonstrated significantly reduced glucose uptake, indicating that, at least at the level of the brush border, glucose transport was still impaired (5). Therefore, administration of EGF to resected animals appears to result in a normalization of glucose transport in intact tissue without an increase in the number of SGLT-1 transporters per unit membrane. Although EGF treatment markedly increases brush border surface area in the distal remnant (5), this does not seem sufficient to account for the magnitude of the increase in glucose absorption in intact tissue. A possible mechanism underlying the beneficial effect of EGF may involve the altered expression of SGLT-1 in enterocytes along the crypt-villus axis. Glucose transport is up-regulated in chronically diabetic rats as a result of the expression of SGLT-1 in a greater number of enterocytes lower down the crypt-villus axis than that seen in normal control animals (6).

Thus, the aim of this study was to examine the effects of massive small bowel resection and EGF treatment on the expression of the sugar transporter SGLT-1 in remnant tissue and to define the mechanisms involved in the chronic regulation of glucose transport in this injury model.

\section{METHODS}

Animal model of massive small bowel resection. All procedures outlined in this study fell within the guidelines set forth by the Canadian Council for Animal Care and the Animal Care Committee at the University of Calgary. New Zealand White rabbits (800-1000 g) were fasted for $24 \mathrm{~h}$ before surgery. Surgical procedures were carried out as previously described (5). Briefly, animals were anesthetized with halothane inhalation anesthetic (halothane, Halocarbon Laboratories, River Edge, NJ, U.S.A.), and a midline laparotomy was performed. The small intestine was resected from $10 \mathrm{~cm}$ distal to the ligament of Treitz, to $15 \mathrm{~cm}$ proximal to the ileocecal valve. The two remaining portions of intestine were then joined by end-to-end anastomosis. The continuity and seal of the anastomosis was assessed by infusing a volume of sterile saline solution (approximately $5 \mathrm{~mL}$ of $0.9 \% \mathrm{NaCl}$ ). The remnant bowel was then replaced into the peritoneal cavity, and the abdominal musculature was closed. Before abdominal closure, $1.5 \mathrm{~mL} / \mathrm{kg}$ Penlong (Penlong XL, Rogar/STP Inc., London, Ontario, Canada) diluted to approximately $12-15 \mathrm{~mL}$ with sterile saline solution was infused into the peritoneal cavity.

Animals were allowed to recover on heating pads for at least $4 \mathrm{~h}$, then placed into separate cages without food. Animals were given another dose of Penlong XL, $24 \mathrm{~h}$ after surgery (1.5 $\mathrm{mL}$ intramuscularly) and then fed ad libitum. Animals were monitored for $10 \mathrm{~d}$ after resection. Control animals consisted of age-matched unmanipulated animals and in the Western blot studies sham-resected animals (distal landmark was transected, and anastomosed as per normal surgical procedures). One group of resected animals was given EGF (recombinant human epidermal growth factor, GF-010-8; Austral Biologicals, San Ramon, CA, U.S.A.; $40 \mu \mathrm{g} / \mathrm{kg}$ diluted in sterile saline solution) daily from $\mathrm{d} 3$ to $\mathrm{d} 8$ by oral gavage at the same time each day. Animals were fasted on d 9 and euthanized (Euthanyl, MTC Pharmaceuticals, Mississauga, Ontario, Canada) on d 10 for analysis. Tissue was harvested beginning $4 \mathrm{~cm}$ distal to the site of anastomosis. In unmanipulated control animals, equivalent tissue was harvested by measuring $10 \mathrm{~cm}$ proximal to the ileocecal valve. In separate experiments, animals were anesthetized and processed for immunohistochemistry.

Analysis of BBM SGLT-1 content by Western immunoblot. BBM were harvested from mucosal scrapings of a $10-\mathrm{cm}$ segment of remnant ileum beginning $4 \mathrm{~cm}$ distal to the site of anastomosis and prepared using the calcium chloride precipitation method described by Kessler et al. (7). BBM purity was assessed by comparing sucrase activity in initial homogenates to BBMs (8). Basolateral contamination was determined by comparing $\mathrm{Na}^{+} / \mathrm{K}^{+}$-ATPase activity of the initial homogenates to the BBM fractions (9). All BBM used had less than $1 \%$ basolateral contamination as assessed by $\mathrm{Na}^{+} / \mathrm{K}^{+} /$ATPase activity, and at least 15 -fold increase in sucrase activity when compared with initial homogenates. BBM were stored in liquid nitrogen until later use.

Aliquots of BBM preparations were assessed for SGLT-1 content by Western immunoblot as previously described (10). The anti-SGLT-1 antibodies used in these studies are described in detail in the section on immunohistochemistry below.

Band density (expressed as units of trace OD) was assessed using a Bio-Rad GS710 Imaging Densitometer and Bio-Rad Quantity One image analysis software (Bio-Rad Laboratories, Mississauga, Ontario, Canada). We have previously documented the validity of this detection system (10). A standard curve of serial dilutions of the peptide against which the antibody was raised demonstrated that trace OD was linear from 0.25 to $7 \mathrm{pmol}$ of the peptide antigen. The immunoreactive bands detected and analyzed in this study fell within the linear range of this detection system. Units are expressed as units of trace $\mathrm{OD} \pm \mathrm{SEM}$.

Preparation of RNA, cDNA synthesis, and cloning of cDNAs. Mucosal scrapings from a 1-cm segment of remnant ileum and corresponding control mucosal scrapings were flashfrozen and stored in liquid nitrogen until extraction. Total RNA was extracted using Trizol reagent (Trizol reagent, 15596; GIBCO Life Technologies, Mississauga, Ontario, Canada) as per manufacturer's instructions. Total RNA was further purified using the RNA cleanup protocol supplied in the RNeasy Mini Kit (RNeasy Mini Kit, 74104; Qiagen, Mississauga, Ontario, Canada). Poly- $\mathrm{A}^{+}$RNA (mRNA) was purified using the polyASpin mRNA Isolation Kit (polyASpin Isolation Kit, 1560; New England Biolabs, Mississauga, Ontario, Canada). An oligo-dT primed (homo-oligomeric DNA pd (T) $)_{12-18}$, 2778503; Pharmacia Biotech, Baie D’Urfe, Quebec, Canada) first-strand cDNA was prepared using Superscript II reverse transcriptase (SuperScript II RNase H-reverse transcriptase, 18064022; GIBCO Life Technologies) and $2 \mu \mathrm{g}$ of poly- $\mathrm{A}^{+}$ 
RNA from a control rabbit as template. A full-length SGLT-1 cDNA was prepared by PCR using primers based on the published rabbit SGLT-1 mRNA sequence obtained from Genbank (accession number M84020), and was subsequently cloned into pBluescript SK (Stratagene, La Jolla, CA, U.S.A.).

Gel electrophoresis and Northern blotting of SGLT-1 $\boldsymbol{m} \boldsymbol{R} \boldsymbol{N} \boldsymbol{A}$. Total RNA samples from remnant ileal tissue from resected animals and resected animals receiving oral EGF and corresponding tissues from controls were diluted to the same final volume containing $1 \mu \mathrm{g}$ of RNA, and then suspended in 2 vol of RNA sample loading buffer (RNA Sample Loading Buffer, R4268; Sigma Chemical Co., St. Louis, MO, U.S.A.), heated to $65^{\circ} \mathrm{C}$ for $10 \mathrm{~min}$, quickly chilled on ice, and run on standard $1 \%$ agarose-formaldehyde gels. Separated RNA was capillary blotted overnight onto Hybond XL (Hybond XL membrane, RPN 1520B; Pharmacia Biotech) using 10× SSC (20× standard saline citrate (SSC), GIBCO 15557044, GIBCO, Mississauga, Ontario, Canada) as a transfer buffer. RNAs were fixed to the membrane using a 5-min incubation on pads of filter paper soaked with $50 \mathrm{mM} \mathrm{NaOH}$. Blots were rinsed briefly in renaturing solution $(87.66 \mathrm{~g} \mathrm{NaCl}, 9.7 \mathrm{~g}$ Tris base, $66.1 \mathrm{~g}$ Tris- $\mathrm{HCl}, 2 \mathrm{~mL} 0.5 \mathrm{M}$ EDTA, in $1 \mathrm{~L}$ douibledistilled $\mathrm{H}_{2} \mathrm{O}, \mathrm{pH}$ 7.4), followed by two to three rinses in $2 \times$ SSC.

Probes $\left(50 \mathrm{ng}\right.$ ) were labeled with $50 \mu \mathrm{Ci}\left[{ }^{32} \mathrm{P}\right] \mathrm{dCTP}$ (Amersham) using a Prime-It II labeling kit (Stratagene; Baie d'Urfe, Quebec) according to the manufacturer's protocol. Membranes were prehybridized at $68^{\circ} \mathrm{C}$ in Expresshyb (Expresshyb solution, 80152; Clontech, Mississauga, Ontario, Canada) in bottles in a hybridization oven. Boiled probes were added to fresh hybridization solution preheated to $68^{\circ} \mathrm{C}$, which was then added to the membranes in the roller bottles. Hybridization was allowed to proceed for $1 \mathrm{~h}$. Filters were washed twice for 10 min each with $2 \times \mathrm{SSC} / 1 \% \mathrm{SDS}$ at room temperature, twice for $15 \mathrm{~min}$ each in $1 \times \mathrm{SSC} / 0.1 \% \mathrm{SDS}$ at $65^{\circ} \mathrm{C}$, and finally for $15 \mathrm{~min}$ at $65^{\circ} \mathrm{C}$ in $0.1 \times \mathrm{SSC}$ in $0.1 \% \mathrm{SDS}$. Membranes were exposed to Kodak Biomax MS film (Kodak Biomax MS and Transcreen HE combo kit, 1017391; Eastman Kodak, Rochester NY, U.S.A.) overnight at $-70^{\circ} \mathrm{C}$. The same blots were stripped by washing five to six times with vigorous agitation in $0.1 \times \mathrm{SSC} / 0.1 \% \mathrm{SDS}$, which had been brought to a boil immediately before use. These stripped membranes were then probed for the housekeeping gene GAPDH to provide an internal standard for each blot. Bands were measured by densitometry (Bio-Rad GS710 Imaging Densitometer and BioRad Quantity One image analysis software; Bio-Rad Laboratories), and expressed as arbitrary units of trace OD \pm SEM.

Immunohistochemical localization of SGLT-1 along the villus axis. In separate experiments, tissues were prepared for immunohistochemical localization of SGLT-1 as previously described (11), with the exception of intraperitoneal sodium pentobarbital as anesthetic $(1 \mathrm{~mL} / \mathrm{kg}$, Somnotol; MTC Pharmaceuticals, Cambridge, Ontario, Canada). Briefly, animals were perfused transcardially with saline, followed by $10 \%$ buffered neutral formalin (R04586; BDH, Toronto, Ontario, Canada). Tissue was then postfixed in $10 \%$ formalin at $4{ }^{\circ} \mathrm{C}$ overnight. Fixed tissues were cryoprotected through a series of graded sucrose-PBS solutions (sucrose, ACS 888; BDH, in diluted 10× Dubelcco's PBS, 14080-055; GIBCO-BRL, Mississauga, Ontario, Canada), and then embedded in OCT embedding media (OCT compound, 4583; Tissue-Tek, Miles Inc., Elkhart, IN, U.S.A.). Serial 7- $\mu \mathrm{m}$ cryosections were mounted directly onto silane-coated slides (silane adhesive, 63411; Electron Microscopy Sciences, Ft. Washington, PA, U.S.A.), and stored at $-20^{\circ} \mathrm{C}$ until further processing for immunofluorescent detection of SGLT-1 as previously described (11). Anti-SGLT-1 polyclonal antibodies were obtained commercially (Cedarlane Laboratories Ltd., Hornby, Ontario, Canada) and were raised in rabbits against a 19-amino acid synthetic peptide corresponding to amino acids $402-420$ of the putative extracellular loop of rabbit intestinal SGLT-1 conjugated to keyhole limpet hemocyanin.

Stained slides were then coverslipped with FluorSave reagent to preserve the fluorescent properties of the secondary antibody, viewed on a fluorescent microscope (Zeiss Axioskop, Toronto, Ontario), and measured using an ocular micrometer. Immunoreactive stain length along the villus axis was coarsely measured by micrometer, and expressed as a ratio of immunoreactive stain distance per entire villus length. To assess the relative pattern of staining intensity along the villus each villus was divided into a villus tip, upper villus, lower villus, and villus bottom. Staining was scored along the villus for each segment by a blinded observer. A score of 2 was given if both sides of the villus demonstrated continuous immunoreactive staining; 1 if staining was present on one or both sides but was discontinuous; and a score of 0 was given if staining was not present. Measurements were converted to log format before statistical analysis.

In situ hybridization to localize SGLT-1 mRNA. Analysis of the full-length SGLT-1 cDNA used for Northern blotting revealed an approximately 200-base region (from nucleotides 237-446) flanked by Bam $\mathrm{H} 1$ and $X h o \mathrm{I}$ restriction sites, which we believed would make an ideal probe for in situ analysis. This fragment was excised and subcloned into pBlueScript SK. Linearized template $(1 \mu \mathrm{g})$ was transcribed to create a digoxigenin ribonucleotide antisense probe using a DIG RNA labeling kit (1175025; Boehringer Mannheim, Indianapolis, IN, U.S.A.) with T3 polymerase (T3 RNA polymerase, 1031163; Boehringer Mannheim) as per manufacturer's instructions. Transcripts were precipitated by addition of $0.1 \mathrm{vol}$ of $4 \mathrm{M}$ $\mathrm{LiCl}$ (L9650; Sigma Chemical Co.), $1 \mu \mathrm{L}$ of glycogen $(20$ $\mathrm{mg} / \mathrm{mL}$ stock G0885; Sigma Chemical Co.), and 2.5 vol of anhydrous ethyl alcohol, and stored at $-70^{\circ} \mathrm{C}$ for at least 30 min. Probes were spun down in a microfuge, washed two times with $70 \%$ ethanol and the pellets were air-dried. Pellets were then resuspended in diethyl pyrocarbonate (DEPC)-treated water. Labeling efficiency and probe concentration was estimated as per manufacturer's instructions.

Tissue preparation and in situ hybridization protocols were performed essentially as described in Muldrew et al. (12) with several minor modifications. Distal remnant tissues and controls were flash-frozen in OCT, and 5- $\mu \mathrm{m}$ rather than $6-\mu \mathrm{m}$ sections were used. Probe concentration was reduced to 100 $\mathrm{ng} / \mathrm{mL}$. In addition, Levamisole $(6 \mathrm{mg} / 30 \mathrm{~mL}$ Buffer 3) was included in the color reaction, which was monitored under a light microscope and stopped with three 5-min washes in 
double distilled $\mathrm{H}_{2} \mathrm{O}$, followed by quick dips in graded ethanols, and coverslipping with Eukitt (Eukitt; O. Kindler Co., Freiburg, Germany).

Statistical analysis. Data are expressed as mean \pm SEM unless otherwise specified. Western immunoblot and Northern blot data were analyzed by one-way ANOVA with StudentNewman-Keuls multiple comparisons post test. Immunohistochemistry measurements were analyzed using nonparametric Kruskal-Wallis using Dunn's post test. Statistical significance was set at $p<0.05$.

\section{RESULTS}

Brush border SGLT-1 content. Analysis of BBM sugar transporter levels from unmanipulated control and transected control groups did not reveal any significant differences, therefore control data were pooled for ease of presentation. Probing with the polyclonal antibody against SGLT-1 revealed one immunoreactive band at roughly $70-75 \mathrm{kD}$, which is in agreement with previous reports for rabbit SGLT-1 $(10,13,14)$. As shown in Figure 1, BBM from remnant tissues contained less SGLT-1 than compared with control BBM (resected, $0.347 \pm$ $0.041, n=10$, versus pooled controls, $0.487 \pm 0.041$ arbitrary units trace $\mathrm{OD}, \mathrm{n}=10, p<0.01)$. Oral EGF therapy did not correct the defect in BBM SGLT-1 content (resected + EGF, $0.357 \pm 0.025, n=5, p<0.05$; Fig. $1 A$ ). Figure $1 B$ shows the results of analysis of arbitrary band density units as a percent of controls. BBM from both resected animals and resected animals receiving oral EGF demonstrated significantly less SGLT-1 than pooled control values.

Northern blot analysis of SGLT-1 mRNA in mucosal scrapings. Northern blots for SGLT-1 mRNA were standard-

A
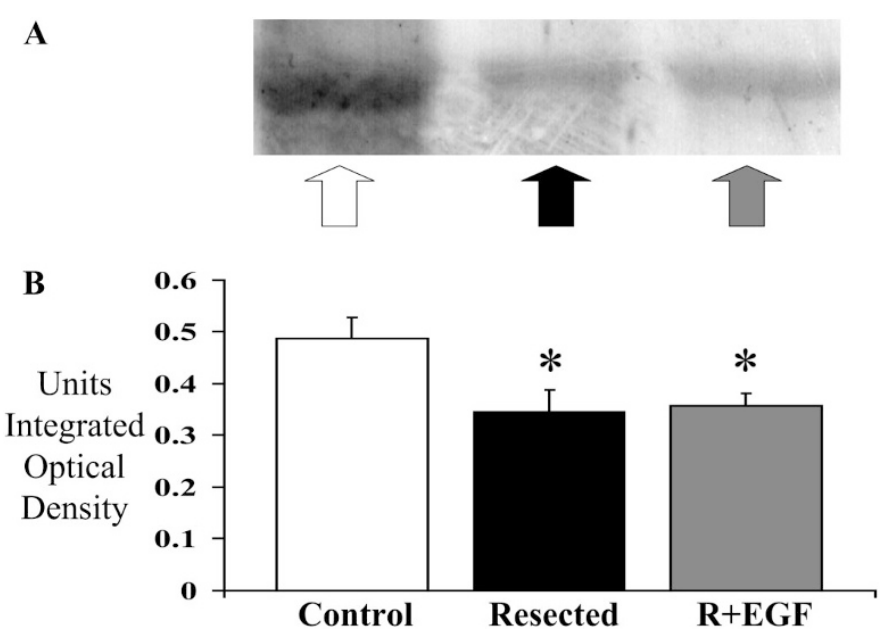

Figure 1. SGLT-1 expression in BBM harvested from control, resected, and oral EGF-treated resected animals $10 \mathrm{~d}$ after surgery. $A$, representative immunoreactive bands corresponding to BBM SGLT-1 from control (left), resected (middle), and oral EGF-treated (right) resected animals. Resected and EGFtreated animals demonstrated decreased SGLT-1 band density when compared with control animals. $B$, densitometric analysis of SGLT-1 immunoreactive bands from control (open), resected (black), and EGF-treated resected animals (gray). Densitometry revealed a significant decrease in the amount of SGLT-1 in BBM harvested from resected animals. Resected animals treated with oral EGF also demonstrated decreased BBMV SGLT-1 content. $n=10$ (control), $n=10$ (resected), $n=5$ (resected + EGF). ${ }^{*} p<0.05$. ized to the internal control GAPDH. Figure $2 A$ depicts representative bands corresponding to SGLT-1 mRNA obtained from mucosal scrapings taken from control animals, resected animals, and resected animals receiving oral EGF therapy. No alteration in band density was observed among groups. These findings were confirmed by densitometry (Fig. 2B). No alteration in the relative levels of SGLT-1 mRNA was detected among any of the groups examined.

Immunohistochemical localization of SGLT-1 along the villus axis. Figure 3 shows representative photomicrographs demonstrating the immunohistochemical localization of SGLT-1 along the villus axis in tissue from control animals, resected animals, and resected + EGF animals. Control tissues demonstrated a reproducible pattern of increasing apical stain intensity from the base of the villus, to the villus tip, with no immunoreactivity observed in the crypt. In remnant tissue a shift in the pattern of SGLT-1 immunoreactivity was noted such that stain intensity peaked near the lower and midvillus region, and decreased toward the villus tip. Tissue from resected animals treated with oral EGF demonstrated a pattern of SGLT-1 immunoreactivity that was indistinguishable from control. Immunofluorescent stain intensity in the villus tip, upper midvillus, lower midvillus, and villus bottom was assessed (Fig. 4). Resection resulted in a downward shift in SGLT-1 staining along the villus compared with controls. EGF treatment returned the staining pattern to that seen in controls.

Measurement of the length of SGLT-1 apical stain was then correlated to the overall crypt-villus length and expressed as a percent of the overall length. These measurements indicated that after resection, villi in the remnant intestine had a larger proportion of villus cells expressing immunoreactive SGLT-1

A
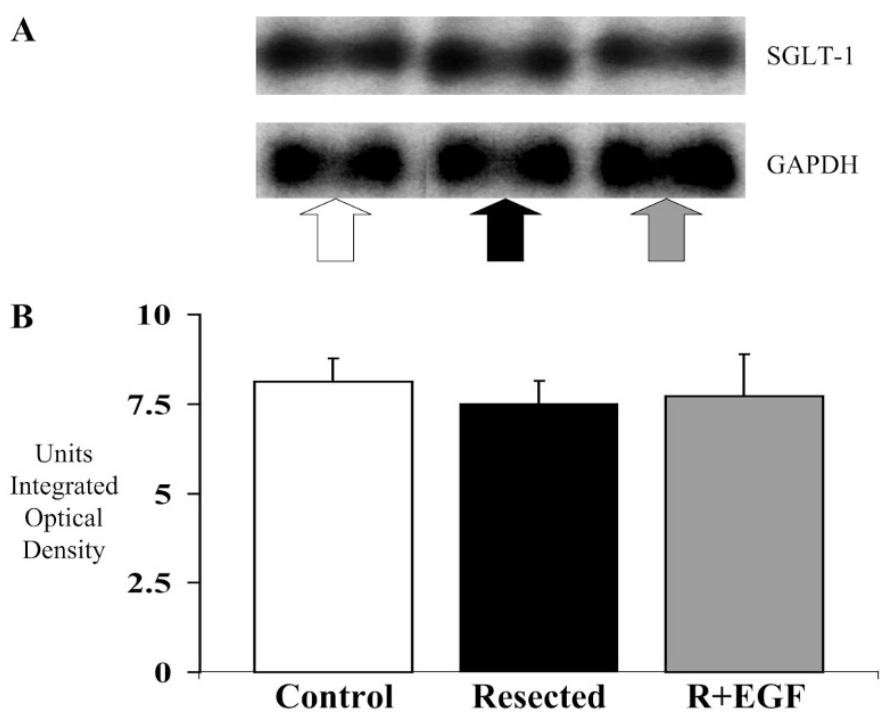

Figure 2. Northern blot analysis of SGLT-1 mRNA content from mucosal scrapings harvested from control, resected, and oral EGF-treated resected animals. $A$, representative SGLT-1 Northern blots and GAPDH internal standards from control (left), resected (middle), and resected + EGF tissues (right). The relative amounts of SGLT-1 mRNA did not differ among treatment groups. $B$, densitometric analysis of Northern blots for mucosal SGLT-1 mRNA. Neither resection nor EGF treatment altered the relative amounts of mucosal SGLT-1 mRNA. $n=8$ (control), $n=4$ (resected), $n=4$ (resected + EGF). 


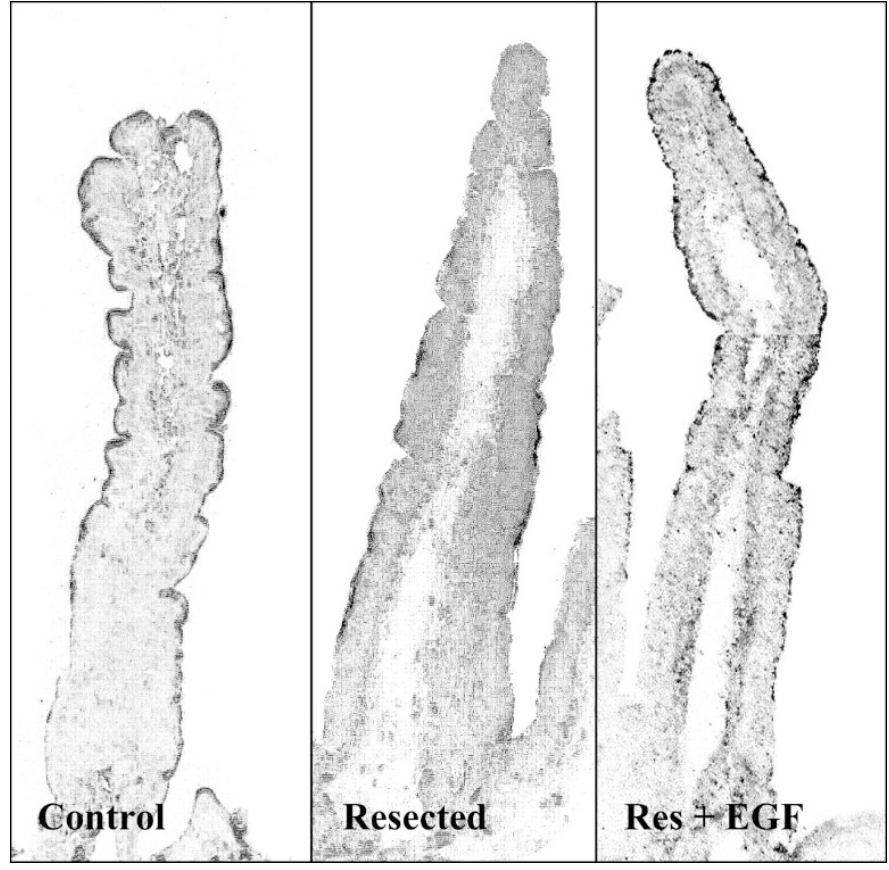

Figure 3. Immunofluorescent localization of SGLT-1 protein along the villus axis $(20 \times$ magnification). Control tissues displayed consistent immunoreactivity (black apical stain) from the base to the tip of the villus. Resected tissues demonstrated a shift in SGLT-1 expression to the lower two thirds of the villus. Oral EGF therapy (Res $+E G F)$ returned the pattern of SGLT-1 immunoreactivity to that observed in controls.

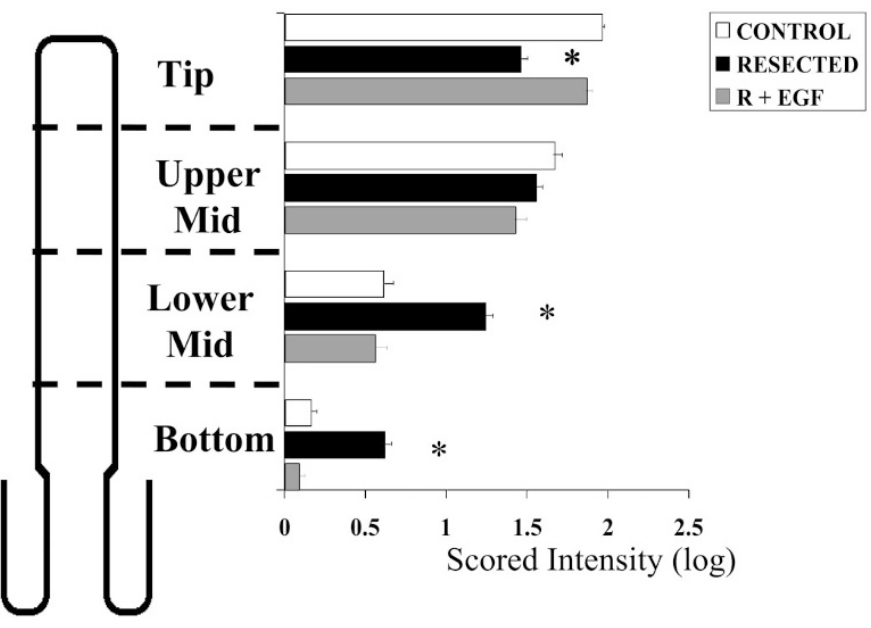

Figure 4. Scored immunofluorescent stain intensity in villus tip, upper midvillus, lower midvillus, and bottom villus. Immunofluorescent staining was significantly reduced in the tip and significantly increased in the lower portions of the villus in resected animals compared with control animals. EGF treatment $(R+E G F)$ returned staining to a pattern similar to that seen in control animals. Control $n=11$, resected $n=16$, R + EGF $n=6 ;{ }^{*} p<0.05$.

when compared with control measurements (Fig. 5; resected, $52.01 \pm 1.03 \%$ versus control, $47.3 \pm 1.12 \%$ crypt-villus length, $n>60$ from 4 animals, $p<0.05$ ). This result indicates that remnant tissue recruits more enterocytes into the glucosetransporting population, albeit in a different region of the villus. In contrast, resected animals receiving oral EGF displayed a normalized ratio of SGLT-1 immunoreactivity to villus-crypt length (Fig. 5; resected + EGF, $43.4 \pm 1.41, n>$ 60 from 4 animals). In EGF-treated animals, the proportion of

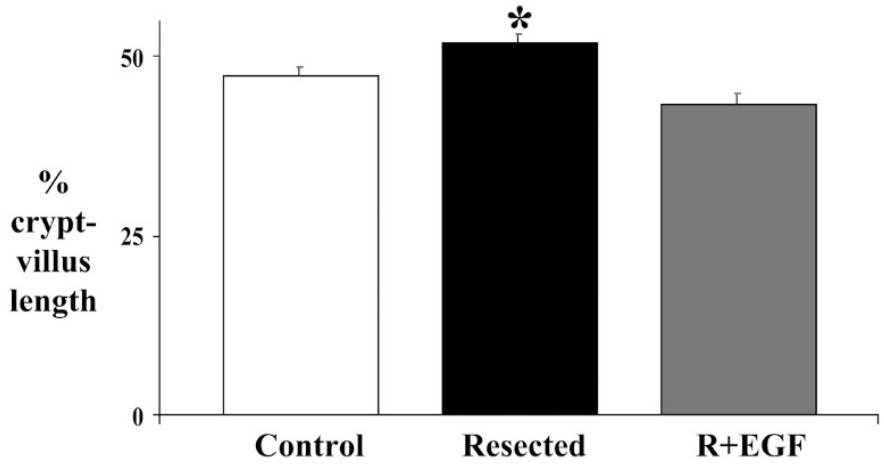

Figure 5. Measurement of the cohesive SGLT-1 immunoreactivity in control (open), resected (black), and resected + EGF animals (gray) as percent of the total villus-crypt length. Remnant tissues demonstrated increased SGLT-1 immunoreactive staining along the crypt-villus axis when compared with control tissues as determined by nonparametric Kruskal-Wallis analysis and Dunn's post test. Resected + EGF tissues demonstrated a normalized ratio of SGLT-1 immunoreactivity to crypt-villus length when compared with control tissues ( $n=4$ animals from each treatment group, $n>60$ measurements per group).

villus length that was stained positive for SGLT-1 was not different from controls, but significantly different from resected tissues $(p<0.05)$.

In situ hybridization to localize SGLT-1 mRNA along the villus axis. Using digoxigenin-labeled antisense probes for an approximately 200-base sequence (nucleotides 237-446) within the SGLT-1 mRNA sequence allowed visualization and localization of SGLT-1 mRNA transcription along the villus axis. Specificity was confirmed by omission of the antisense probe. Initial experiments outlined the importance of including Levamisole in the color detection buffer to inhibit endogenous phosphatase activity. Sections incubated without antisense probe, and in the presence of Levamisole in the color detection buffer, did not display any color reaction (data not shown).

Figure 6 shows representative photomicrographs demonstrating the results of in situ hybridization for SGLT-1 mRNA

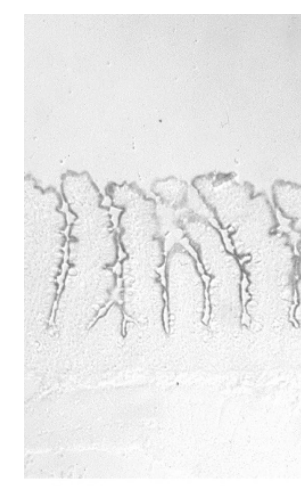

Control

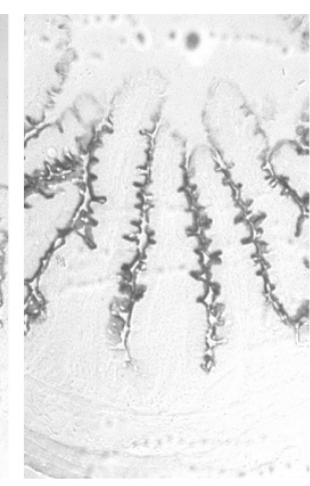

Resected

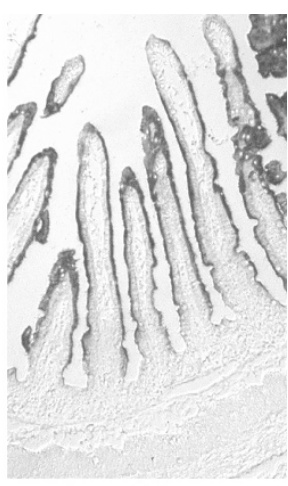

Res + EGF
Figure 6. In situ hybridization for SGLT-1 mRNA ( $25 \times$ magnification). Control tissues demonstrated consistent hybridization for SGLT-1 mRNA from the base to the tip of the villus. Resection altered SGLT-1 mRNA expression along the villus axis. Probe hybridization displayed a pattern similar to that seen for SGLT-1 protein, with mRNA expression at the base of the villus, and little or no mRNA at the villus tip. Oral EGF (Res + EGF) normalized SGLT-1 mRNA expression to control patterns ( $n=4$ animals for each treatment group). 
in tissue from control animals, resected animals, and resected + EGF animals. Control tissues demonstrated the presence of SGLT-1 mRNA from the base of the villus, with a slight decrease in intensity near the villus tip. No SGLT-1 mRNA was localized to the crypt epithelial cells, nor did the probe hybridize cells within the lamina propria region. In contrast, in remnant tissue from resected animals, a visible decrease in SGLT-1 mRNA hybridization was observed in the region of the villus tip. This pattern of SGLT-1 mRNA localization corresponded to the altered expression pattern of SGLT-1 protein when assessed by immunohistochemistry. Treatment with oral EGF returned the pattern of SGLT-1 mRNA hybridization back to the normal control pattern, with message distributed from the base of the villus to the tip.

\section{DISCUSSION}

The findings from the current study suggest that the decrease in glucose transport function observed in remnant bowel is caused in part by an alteration in the expression of SGLT-1 mRNA and protein, leading to a shift in SGLT-1 localization from the villus tip to the midvillus region, in addition to the decrease in SGLT-1 protein content. EGF treatment improves glucose transport function by returning the pattern of SGLT-1 expression to that seen in normal animals. In control tissue, SGLT-1 protein was expressed from the base of the villus to the villus tip with staining intensity being greatest at the tip. In remnant tissue SGLT-1 was expressed primarily in the midvillus region with little staining at the villus tip. EGF treatment normalized the pattern of SGLT-1 along the crypt-villus axis. Likewise a similar pattern was observed for SGLT-1 mRNA. Resection caused a decrease in SGLT-1 mRNA expression at the villus tip in remnant tissue that was returned to the control pattern after EGF treatment.

In the current study, EGF was administered orally, once a day, at the same time each morning, for a period of $5 \mathrm{~d}$. A body of evidence has accumulated indicating orally administered EGF can influence the adaptive response after small bowel resection $(4,5,15,16)$. Surgical removal of the submandibular gland, the major source of endogenous EGF, diminished the adaptive response after resection whereas oral administration of EGF to replace that lost by sialoadenectomy was shown to restore the adaptive response to normal (15). Similarly, mice overexpressing EGF in the small intestine showed marked improvement in their adaptive responses after resection (17). Finally, recent studies have indicated the presence of EGF receptors on the apical BBM in normal small intestinal tissue, as well as after massive small bowel resection (18-20).

A dose of $40 \mu \mathrm{g}$ of EGF $/ \mathrm{kg}$ per day was administered to resected animals in this study. Early work in the laboratory demonstrated that this dose of EGF, delivered orogastrically, significantly increased mucosal DNA in the distal small intestine and induced precocious maturation of intestinal brush border disaccharidases (21). As this dose was shown to produce a significant effect on intestinal function and development, it was subsequently used to examine the effect of EGF on adaptation in remnant bowel after massive small bowel resection.
The data suggests that a number of mechanisms are involved in the chronic regulation of sugar transport in the small intestine. At the cellular level, resection results in a decrease in the relative amounts of brush border SGLT-1. The reduction in BBM SGLT-1 correlates with the observed decrease in brush border glucose uptake kinetics (22). This decrease in BBM SGLT-1 concentration does not appear to be the result of a decrease in the overall amount of mRNA for these transporters.

Oral EGF therapy normalizes glucose transport in intact remnant tissue after resection (4), but this is not because of an increase in the amount of SGLT-1 per unit of membrane. SGLT-1 content in BBM from EGF-treated resected animals was not different from BBM prepared from remnant tissue from resected animals (5). Therefore, the recovery of function seen in intact remnant tissue in EGF-treated resected animals must involve other variables. Oral EGF treatment significantly increased brush border height over that seen in resected remnant tissue (5). As BBM glucose uptake kinetics were normalized to unit membrane protein, as were Western immunoblots for BBM SGLT-1, the compensation seen in intact tissues is likely in part the result of an overall increase in the absolute amount of SGLT-1 expressed along the brush border. Therefore, although the BBM in resected remnant tissue might be less functional as shown by Western immunoblot and glucose uptake kinetics, there is more of this membrane inserted into the brush border of animals receiving oral EGF. Studies in other laboratories have also reported a beneficial effect of EGF on SGLT-1 expression in the adapting bowel (23). Both sucrase and SGLT-1 content were reported increased in isolated enterocytes obtained from remnant bowel. Administration of EGF to resected animals resulted in a further increase in SGLT-1 expression over resection alone although sucrase was not altered. It is unknown whether the observed defect in transport function per unit of membrane protein in EGF-treated animals returns to a more normal value at a later time. Evidence from other studies suggests that adaptive changes in bowel function and structure may or may not persist depending on the factor examined. The increase in brush border surface area reported $10 \mathrm{~d}$ after surgery in remnant bowel returns to normal values by $21 \mathrm{~d}$ (5). Increases in villus height appear to remain elevated for an extended period after surgery (24-26). Other studies measuring functional changes reported disparate findings. Mucosal disaccharidase activity has been reported to both decrease after resection but return to control values at later time points (4) and to increase in the initial postsurgical period and remain elevated (25). Glucose transport in remnant tissue is depressed $10 \mathrm{~d}$ after surgery and remains so at $21 \mathrm{~d}(4,5)$. In contrast transport-specific activities were reported generally decreased 2 wk after resection but had either increased or returned to control values by $4 \mathrm{wk}$ (24). The findings to date suggest that as bowel surface area increases with time, alterations in enterocyte function may return to more normal values.

The expression of SGLT-1 protein along the crypt-villus axis in remnant tissue was markedly different from the pattern of SGLT-1 expression observed in control tissue. Control tissues demonstrated a gradual increase in SGLT-1 stain intensity from the base of the villus toward the villus tip similar to 
what others have reported (27-29). Remnant tissue displayed altered SGLT-1 expression along the villus axis, with the majority of stain occurring near the midvillus, and greatly decreased immunoreactivity at the villus tip. The significance of the altered pattern of SGLT-1 immunolocalization on the transport function of the tissue is not known. However, as EGF-treated tissues demonstrated a pattern of SGLT-1 protein expression similar to control tissue, increasing from the base to the tip of the villus, the normalization of SGLT-1 localization along the villus axis may be responsible for the improvement in glucose transport capacity seen in intact EGF-treated remnant tissue (4). Despite a decrease in BBM SGLT-1 concentration and glucose uptake kinetics, the localization of SGLT-1 to the upper villus region might improve the access of the transporter to the luminal glucose load.

In situ hybridization for SGLT-1 mRNA in control tissues demonstrated a consistent pattern of staining from the base of the villus to the villus tip. The pattern of SGLT-1 mRNA hybridization is in agreement with other studies examining the distribution of SGLT-1 mRNA along the crypt-villus axis (30-32). Remnant tissue demonstrated an altered pattern of SGLT-1 mRNA expression along the villus with expression at the base of the villus but little or no expression at the villus tip. Oral EGF treatment normalized the pattern of SGLT-1 expression along the villus to that seen in control tissue. This apparent decrease in SGLT-1 mRNA per enterocyte is particularly interesting as EGF stimulation has been reported to decrease Sp1 binding activity, and Sp1 binding has been implicated in maintaining basal levels of SGLT-1 mRNA transcription $(33,34)$.

A number of variables appear to be involved in adaptation in remnant tissue: 1) an increase in villus height and subsequent expansion of the transporting compartment, 2) the insertion of additional less functional microvillus membrane into the brush border and the subsequent increase in absolute SGLT-1 expression, and 3) a downward shift in SGLT-1 expression along the villus axis. EGF enhances adaptation in remnant tissue by stimulating 1 ) a further increase in microvillus membrane insertion above that induced by resection alone, and 2) by the normalization of SGLT-1 expression along the crypt-villus axis.

The mechanisms behind the alterations in SGLT-1 expression seen in remnant tissue are unknown but may involve the increase in enterocyte migration rate observed in remnant tissue in our laboratory (5) and others (35). Other studies have demonstrated that the number of apoptotic enterocytes is significantly increased at the villus tip in remnant tissue (36), and EGF has been shown to inhibit apoptosis in remnant bowel (37). Enterocyte migration rate is increased almost 6-fold in remnant tissue compared with control tissue (5). Thus, resection might lead to an increase in enterocyte migration rate, which induces premature expression of SGLT-1 and early programmed cell death. EGF may provide clinical benefit both by increasing microvillus absorptive surface area and by normalizing the rate of enterocyte migration and maturation.

\section{CONCLUSIONS}

In conclusion, the findings indicate that the defect in glucose transport observed in remnant tissue is caused by a redistribu- tion of SGLT-1 protein and message along the villus length as well as a reduction in overall SGLT-1 expression. EGF enhances glucose transport in remnant tissue in part by returning the pattern of SGLT-1 protein and message expression to that seen in control tissue. This suggests that the functional activity of SGLT-1 is dependent on where it is expressed along the villus axis.

\section{REFERENCES}

1. Strong SA, Fazio VW 1999 Surgical treatment of inflammatory bowel disease. Curr Opin Gastroenterol 15:326-330

2. Buchman AL, Moukarzel AA, Ament ME, Eckert C, Bhuta S, Mestecky J, Hollander D 1994 Effects of total parenteral nutrition on intestinal morphology and function in humans. Transplant Proc 26:1457

3. Smith CE 1993 Quality of life in long-term total parenteral nutrition patients and their family caregivers. J Parenter Enteral Nutr 17:501-506

4. O'Loughlin EV, Winter M, Shun A, Hardin JA, Gall DG 1994 Structural and functional adaptation following jejunal resection in rabbits: effect of epidermal growth factor. Gastroenterology 107:87-93

5. Hardin JA, Chung B, O'Loughlin EV, Gall DG 1999 The effect of epidermal growth factor on brush border surface area and function in the distal remnant following resection in the rabbit. Gut 44:26-32

6. Fedorak RN, Cheeseman CI, Thomson ABR, Porter VM 1991 Altered glucose carrier expression: mechanism of intestinal adaptation during streptozocin-induced diabetes in rats. Am J Physiol 261:G585-G591

7. Kessler M, Acuto O, Storelli C, Murer H, Muller M, Semenza G 1978 A modified procedure for the rapid preparation of efficiently transporting vesicles from small intestinal brush border membranes. Their use in investigating some properties of D-glucose and choline transport systems. Biochim Biophys Acta 771:35-41

8. Dahlquist A 1964 Method for assay of intestinal disaccharidases. Anal Biochem $7: 18-25$

9. Kelly M, Butler DG, Hamilton JR 1972 Transmissable gastroenteritis in piglets: a model of infantile viral diarrhea. J Pediatr 80:925-931

10. Chung BM, Wong JK, Hardin JA, Gall DG 1999 Role of actin in EGF-induced alterations in enterocyte SGLT1 expression. Am J Physiol 276:G463-G469

11. Chung BM, Wallace LE, Hardin JA, Gall DG 2002 The effect of epidermal growth factor on the distribution of SGLT-1 in rabbit jejunum. Can J Physiol Pharmacol 80:872-878

12. Muldrew K, Chung M, Novak K, Schachar NS, Zernicke RF, McGann LE, Rattner JB, Matyas JR 2001 Evidence of chondrocyte repopulation in adult ovine articular cartilage following cryoinjury and long-term transplantation. Osteoarthritis Cartilage 9:432-439

13. Hediger MA, Mendlein J, Lee H-S, Wright EM 1991 Biosynthesis of the cloned intestinal $\mathrm{Na}^{+}$/glucose cotransporter. Biochim Biophys Acta 1064:360-364

14. Schmidt U, Eddy B, Fraser CM, Venter JC, Semenza G 1983 Isolation of (a subunit of) the $\mathrm{Na}^{+} / \mathrm{D}$-glucose cotransporter(s) of rabbit intestinal brush border membranes using monoclonal antibodies. FEBS Lett 161:279-283

15. Helmrath MA, Shin CE, Fox JW, Erwin CR, Warner BW 1998 Adaptation after small bowel resection is attenuated by sialoadenectomy: The role for endogenous epidermal growth factor. Surgery 124:848-854

16. Iannoli P, Miller JH, Sax HC 1998 Epidermal growth factor and human growth hormone induce two sodium-dependent arginine transport systems after massive enterectomy. J Parenter Enteral Nutr 22:326-330

17. Erwin CR, Helmrath MA, Shin CE, Falcone Jr RA, Stern LE, Warner BW 1999 Intestinal overexpression of EGF in transgenic mice enhances adaptation after small bowel resection. Am J Physiol 277:G533-G540

18. Thompson JF 1988 Specific receptors for epidermal growth factor in rat intestinal microvillus membranes. Am J Physiol 254:G429-G435

19. Wallace LE, Chung BM, Hardin JA, Gall DG 2000 Expression of EGF, and erbB receptor proteins in jejunal epithelium. Gastroenterology 118:A2918(abstr)

20. Avissar N, Wang HT, Miller J-NH, Iannoli P, Sax HC 2000 Epidermal growth factor receptor is increased in rabbit intestinal brush border membrane after resection. Dig Dis Sci 45:1145-1152

21. O'Loughlin EV, Chung M, Hollenberg MD, Hayden J, Zahavi I, Gall DG 1985 Effect of epidermal growth factor on ontogeny of the gastrointestinal tract. Am J Physiol 249:G674-G678

22. Wright EM, Turk E, Hager KM, Lescale-Matys L, Hirayama BA, Supplisson S, Loo DDF $1992 \mathrm{The} \mathrm{Na}^{+}$/glucose cotransporter (SGLT1). Acta Physiol Scand 146:201-207

23. Dunn JC, Parungo CP, Fonkalsrud EW, McFadden DW, Ashley SW 1997 Epidermal growth factor selectively enhances functional enterocyte adaptation after massive small bowel resection. J Surg Res 67:90-93

24. Urban E, Michel AM 1983 Separation of adaptive mucosal growth and transport after small bowel resection. Am J Physiol 244:G295-G300

25. Swaniker F, Guo W, Fonkalsrud EW, Brown T, Newman L, Ament M 1995 Adaptation of rabbit small intestinal brush-border membrane enzymes after extensive bowel resection. J Pediatr Surg 30:1000-1003

26. Sigalet DL, Martin GR, Poole A 2000 Differential sugar absorption as a marker for adaptation in short bowel syndrome. J Pediatr Surg 35:661-664

27. Takata K, Kasahara T, Kasahara M, Ezaki O, Hirano H 1992 Immunohistochemical localization of $\mathrm{Na}^{+}$-dependent glucose transporter in rat jejunum. Cell Tissue Res 267:3-9

28. Dong R, Srai SK, Debnam E, Smith M 1997 Transcriptional and translational control over sodium-glucose-linked transporter (SGLT1) gene expression in adult rat small intestine. FEBS Lett 406:79-82 
29. Shirazi-Beechey SP, Dyer J, Bagga K, Simmonds R, Wood IS, Allison GG, Scott D, King TP 1997 Molecular events involved in glucose-induced intestinal $\mathrm{Na}^{+} / \mathrm{D}-$ glucose co-transporter (SGLT1) expression. Biochem Soc Trans 25:958-962

30. Freeman TC, Collins AJ, Heavens RP, Tivey DR 1993 Genetic regulation of enterocyte function: a quantitative in situ hybridisation study of lactase-phlorizin hydrolase and $\mathrm{Na}^{+}$-glucose cotransporter mRNAs in rabbit small intestine. Pflugers Arch 422:570-576

31. Hwang E-S, Hirayama BA, Wright EM 1991 Distribution of the SGLT1 $\mathrm{Na}^{+} /$glucose cotransporter and mRNA along the crypt-villus axis of rabbit small intestine. Biochem Biophys Res Commun 181:1208-1217

32. Smith MW, Turvey A, Freeman TC 1992 Appearance of phloridzin-sensitive glucose transport is not controlled at mRNA level in rabbit jejunal enterocytes. Exper Physiol 77:525-528
33. Mortensen ER, Marks PA, Shiotani A, Merchant JL 1997 Epidermal growth factor and okadaic acid stimulate Sp1 proteolysis. J Biol Chem 272:16540-16547

34. Martin MG, Wang J, Solorzano-Vargas RS, Lam JT, Turk E, Wright EM 2000 Regulation of the human $\mathrm{Na}\left({ }^{+}\right)$-glucose cotransporter gene, SGLT1, by HNF-1 and Sp1. Am J Physiol Gastrointest Liver Physiol 278:G591-G603

35. Menge H, Hopert R, Alexopoulos T, Riecken E-O 1982 Three-dimensional structure and cell kinetics at different sites of rat intestinal remnants during the early adaptive response to resection. Res Exp Med (Berl) 181:77-94

36. Thompson JS, Barent B 1999 Effects of intestinal resection on enterocyte apoptosis. J Gastrointest Surg 3:672-677

37. Stern LE, Falcone Jr RA, Huang F, Kemp CJ, Erwin CR, Warner BW 2000 Epidermal growth factor alters the bax:bcl-w ratio following massive small bowel resection. J Surg Res 91:38-42 